\title{
The Dynamic Relationship between Tourism and Economy: Evidence from Nepal
}

\author{
Dipendra Karki ${ }^{1}$
}

\begin{abstract}
The objective of this paper is to analyse the role of tourism in the Nepalese economic growth. I use a trivariate model of real Gross Domestic Product (GDP), international tourist arrivals and real effective exchange rate to investigate the long-run and short-run relationship between tourism and economic growth. The Augmented Dickey-Fuller (ADF) test is used to determine the order of integration of the series, and I employ the Engle-Granger cointegration procedure to test for the presence of long-run relationship. By using annual macroeconomic data for Nepal for the period of 1962-2011, results reveal that there is a cointegrating relationship between tourism and economic growth.
\end{abstract}

Keywords: Tourism, Economic Development, Nepal

\section{Introduction}

The tourism industry is a relatively new phenomenon in international economic trades. Nowadays, it contributes to the foreign income sources of many nations. It also plays a significant role in the economic, cultural and social development of many countries. In developing countries, where problems such as high rate of unemployment, limited foreign exchange resources and single-product economy prevail, development of tourism industry plays an important role in the country's economy.

International tourism has grown rapidly in Nepal over the last decade, however, the rate of growth varied from year to year. In Nepal, tourism is expected to support directly 293,000 jobs (2.4\% of total employment) and the total contribution to employment, including jobs indirectly supported by the industry, is 726,000 jobs $(5.9 \%$ of total employment) in 2011. With many historical, religious and natural attractions, Nepal has the potential to become one of the tourist attractions in the world.

In recent years, researchers have been interested in the relationship between tourism and economic growth, empirically supporting a direct effect from the first to the second. A general consensus has emerged that it increases foreign exchange income, creates employment opportunities, stimulates the growth of the tourism

\footnotetext{
${ }^{1}$ PhD Scholar, Kathmandu University, School of Management
}

industry and therefore triggers overall economic growth. As such, tourism development has become a common awareness in political authorities worldwide.

\section{Literature Review}

Zortuk (2009) and Gunduz and Hatemi-J (2005), in their analyses conducted on Turkish economy, concluded that the increase in tourism income effects economic growth. Oh (2005) found that the hypothesis of tourism-led economic growth could not be verified in the case of the Korean economy. The results of Oh's Granger causality test imply the existence of a one-way causal relationship in terms of economics-driven tourism growth. On the other hand, the analyses by Dritsakis (2004) on Greece, Durbarry (2004) on Mauritius and Balaguer and Cantavella-Jorda (2002) on Spain empirically proved the existence of a bidirectional relationship between the two variables. In addition, Eugenio-Martin and Morales (2004) confirm the validity of tourism-led growth hypothesis for low and middle income countries in Latin America while they assert that the situation is different for high income countries.

Lee and Chang's study (2008), containing thirty two selected countries including both OECD countries and non-OECD countries, found that there is a unidirectional relationship running from tourism towards growth 
for OECD countries whereas a bidirectional causality relationship exists for non-OECD coun tries.

Adding to previous literature, the aim of this paper is to investigate whether tourism has really contributed to the economic growth in Nepal. The rest of the paper is organized as follows. Section 3 describes the data and a presentation of the methodology. Section 4 contains empirical results and their interpretation. Finally, section 5 offers a summary and conclusions.

\section{Data and Methodology}

There are several alternatives to measure the volume of tourism. One of them is tourism receipt, which is the volume of earnings generated by foreign visitors. A second one is the number of nights spent by visitors from abroad. A third one is the number of tourist arrivals. However, this study makes use of tourist arrivals to represent tourism, since the problem of multicollinearity emerges when tourism receipts are used. Given that the tourism-led growth hypothesis is about contribution of tourism to the economic growth, real GDP is also included to represent the economic growth. Therefore, we estimate the following equation:

$\ln \mathrm{GDPR}_{\mathrm{t}}=\alpha+\mathrm{a}_{1} \ln \mathrm{TAR}_{\mathrm{t}}+\alpha_{2} \ln \mathrm{REXR}_{\mathrm{t}}+\boldsymbol{e}_{\mathrm{t}} \ldots \ldots .(1)$

Where,

GDPR = natural logarithm of Gross Domestic Product at constant prices,

TAR = natural logarithm of tourist arrivals,

REXR = natural logarithm of real effective exchange rate,

$\boldsymbol{e}=$ the error term with the conventional statistical properties.

Many authors, such as Oh (2005), Gunduz and Hatemi-J. (2005), Dritsakis (2004) and Balaguer and CantavellaJorda (2002) suggest the inclusion of real exchange effective rate in the discussion of international tourism in order to deal with potential overlooked variable problems and to account for external competitiveness.

Since this research note attempts to investigate the validity of tourism-led growth hypothesis for Nepal, the fact that lnREXR could be zero it does not affect the specification of our model. In addition, Gunduz and Hatemi-J (2005), Oh (2005) and Tang (2011) apply a double-log bivariate model to examine the relationship between tourism and economic growth, omitting real effective exchange rate. Employing also a trivariate model to check for robustness, they found no additional evidence against the bivariate model.

The data used in this study are annual time series for the period 1962-2011. The data are obtained from different sources; the tourists arrival data are obtained from statistics on tourism for Nepal (Nepal Tourism Statistics, 2011; annual statistical report) and Ministry of Culture, Tourism and Civil Aviation of Nepal. The GDPR and REXR data are obtained from World Bank database.

The modeling strategy adopted in this study is based on the now widely used Engle-Granger methodology (Engle and Granger, 1987). Testing for cointegration involves two steps:

\subsection{Unit Root Test}

The first step is to determine whether the variables we use are stationary or non-stationary. Running a regression of non-stationary variables may lead to spurious regression problem. Hence, examination of a long-run relation requires that a Cointegration test be carried out. To this end, the augmented Dickey-Fuller (ADF) test of stationarity is performed both on the levels and the first differences of the variables (Dickey and Fuller, 1981). The objective of carrying out a cointegration analysis is to determine the order of integration of the variables. If a series $\left\{y_{t}\right\}$ is not stationary while the first difference $\left\{\mathrm{Dy}_{\mathrm{t}}\right\}$ appear to be stationary then the series is said to be integrated of order 1 (unit root) denoted as I (1). A series in integrated of order d, I ( $d$ ) if it can be difference d times to achieve stationarity. The ADF unit root tests uses the various specifications of the following regression:

$\Delta \mathrm{Y}_{\mathrm{t}}=\beta_{1}+\beta_{2 \mathrm{t}}+\delta+\boldsymbol{e}_{\mathrm{t}}$

Where,

$\mathrm{Y}_{\mathrm{t}}=$ the level of the variable under consideration,

$\Delta$ represents first-differences and $\beta$ is constant term, $\mathrm{t}=$ deterministic time term,

$\boldsymbol{e}_{\mathrm{t}}=$ normally distributed random error term with zero mean and constant variance.

$\Delta \mathrm{Y}_{\mathrm{t}-\mathrm{i}}$ are added to correct for serial correction in the error term $\left(\boldsymbol{e}_{\mathrm{t}}\right)$. 
We used the ADF to test the unit root hypothesis in the logarithm of all the variables considered in the study. The null hypothesis for a unit root in yt against the alternative is stated as:

$\mathrm{H}_{0}: \alpha=0$ vs $\mathrm{H}_{1}: \alpha<0$

The number of lags in the ADF test is determined using the Schwarz information criteria and an initial maximum lag length 4 is used in the test. The criteria evaluates the significance of the fourth lag using the $t$-statistic associated with the lag and sequentially reduce the lag until a significant lag is obtained.

\subsection{Cointegration Test}

In the second step, cointegration test is performed to identify the existence of a long-run relationship. Cointegration concept was introduced through the works of Engle and Granger (1987) and Johansen (1988) seminal papers. Cointegration test is conducted to ascertain if there is any long-run relationship between two or more non-stationary time series. The existence of a long-run or equilibrium relationship among a set of non-stationary time series implies that their stochastic trends must have commonality. Individually, the series may drift or wander apart, but in the long run they will move together to restore equilibrium, since, equilibrium relationship means that the variable cannot move independently of each other. This linkage among the stochastic trends necessitates that the variables are cointegrated (Enders, 2004). The cointegration test used Engle-Granger two-step procedure; which involve estimating the cointegrating regression equation (3.4) using Ordinary Least Squares (OLS) and then conducting unit root tests for the residuals $\mathrm{e}_{\mathrm{t}}$. According to Engle and Granger (1987), the stationarity of the residuals of the regression implies that the series are cointegrated.

$\mathrm{Y}_{\mathrm{t}}=\beta \mathrm{X}_{\mathrm{t}}+\boldsymbol{e}_{\mathrm{t}}$

Where, both $Y_{t}$ and $X_{t}$ are non stationary variables and integrated of order 1 (i.e. $Y_{t} \sim I(1)$ and $X_{t} \sim I(1)$ ). In order for $Y_{t}$ and $X_{t}$ to be cointegrated, the necessary condition is that the estimated residuals from Eq. (3) should be stationary (i.e. $\boldsymbol{e}_{\mathrm{t}} \sim \mathrm{I}(0)$ ).

\subsection{Error Correction Model}

The error correction model help to capture the rate of adjustment taking place among the various variables to restore long-run equilibrium in response to short-term disturbances due to the impact of tourism in GDP of Nepal. According to the Granger representation theorem (Granger, 1983; Engle and Granger, 1987), if a set of variables are cointegrated, then there exists a valid errorcorrection mechanism. Hence, a necessary and sufficient condition for cointegration is the existence of an error correction mechanism (ECM). If we denote our dependent variable GDPR as yt and the entire explanatory variables in equation (1) as $x_{t}$, there exist an error-correction representation of the form:

Given that; $\mathrm{zt}=\left[\frac{y_{t}}{x_{t}}\right] \sim C I(1,1), \beta^{\prime} z_{z=1}=e_{t}$

$\Delta y_{t}=\alpha_{1}+\phi_{1}\left(\beta^{\prime} \mathrm{z}_{\mathrm{t}-1}\right)+\sum_{i=1}^{k} \varphi_{j} \Delta z_{t-j}+v_{\mathrm{t}} \ldots \ldots(4)$

$\Delta x_{t}=\alpha_{2}+\phi_{2}\left(\beta^{\prime} z_{t-1}\right)+\sum_{i=1}^{k}{ }_{j} \Delta z_{t-j}+v_{t}$

Where, Zt refers to deviation of a variable from its longrun path given by $\mathrm{I}(1)$ variables and $v \mathrm{t}$ and ut are wellbehaved error terms and $|\mathrm{f} 1|+|\mathrm{f} 2| \neq 0$. If all terms in the ECM are I(0) 'stationary', then there is no inferential problem and it can be estimated by the OLS method. The error correction models above describe how yt and xt behave in the short-run consistent with a long-run relationship. A significant error correcting parameter indicates that cointegration indeed exist among the variables. Hence, ECM also serves as a confirmatory test for cointegration.

Conditional on finding cointegration between $Y_{t}$ and $X_{t}$, the estimated residuals $(\beta)$ from the first step long-run regression (3) may then be imposed in the error correction term $\left(Y_{t}-\beta X_{t}\right)$ in the following equation.

$\Delta \mathrm{Y}_{\mathrm{t}}=\alpha_{1} \Delta \mathrm{X}_{\mathrm{t}}+\alpha_{2}(\mathrm{Y}-\beta \mathrm{X})_{\mathrm{t}-1}+\varepsilon_{\mathrm{t}}$

Where, $\Delta$ represents first-differences and $\varepsilon_{t}$ is the error term. Note that the estimated coefficient $\alpha_{2}$ in the equation should have a negative sign and be statistically significant. Note also that, to avoid an explosive process, the coefficient should take a value between -1 and 0 . According to the Granger Representation 
Theorem (GRT), negative and statistically significant $\alpha_{2}$ is a necessary condition for the variables in hand to be cointegrated.

\section{Empirical Analysis}

Many macroeconomic time series contain unit roots dominated by stochastic trends as developed by Nelson and Plosser (1982). Knowing that unit root tests are sensitive to the presence of deterministic regressors, three models are estimated. The most general model with an intercept (constant) and time trend is estimated first and restrictive models, i.e. with an intercept and without either intercept or trend, respectively, are estimated thereafter. Unit root tests for each variable then is performed on both levels and first differences of variables. Table I reports the ADF test results for the model without constant, with constant, and with constant and trend. It can be seen that the null hypothesis of non-stationarity cannot be rejected at the $5 \%$ level for the levels of all the variables (test without constant and with constant and trend). However, when first differences are taken, the null hypothesis of non-stationarity is rejected for all the variables. Hence, it is concluded that the three variables are integrated of order one I(1). Similarly no autocorrelation is found within the variables which is tested with calculated rho ( $\rho)$ value by using formula; $\mathrm{D}=2(1-\rho)$. If the value falls is close to 0 that will be the indication of negative autocorrelation and if it is close to 4 that will indicate positive autocorrelation. But if the value falls near to 2 no autocorrelation shall be revealed. This result is consistent to the finding of Nelson and Plosser (1982) that most of the macroeconomic variables are non-stationary at level, but they are stationary after first differencing.

The ADF tests results for the all variables indicate that they all are integrated of the same order, we then proceed to test for cointegration (long-run relationship) for the variables. In order to estimate the long-run relationship between variables using the Engle and Granger integration technique, first, it is to find the optimal order of the VAR model using lag determining criteria. Then, one can estimate the long-run relationship between variables.
Table I : Results of Unit Root Tests

\begin{tabular}{|c|c|c|c|c|c|}
\hline \multirow[b]{2}{*}{ Test } & \multirow[b]{2}{*}{ Variable } & \multicolumn{4}{|c|}{ Augmented Dickey-Fuller (ADF) } \\
\hline & & Levels & $(\rho)$ & $\begin{array}{c}\text { First } \\
\text { Differences }\end{array}$ & $(\rho)$ \\
\hline \multirow{3}{*}{$\begin{array}{l}\text { Without } \\
\text { Constant }\end{array}$} & $\operatorname{lnGDPR}$ & $\begin{array}{c}7.3560 \\
(1)\end{array}$ & 0.001 & $\begin{array}{c}1.9016 \\
(0.0446)\end{array}$ & -0.229 \\
\hline & $\operatorname{lnTAR}$ & $\begin{array}{l}2.2899 \\
(0.995)\end{array}$ & 0.013 & $\begin{array}{c}-3.1415 \\
(0.001)\end{array}$ & 0.018 \\
\hline & $\operatorname{lnREXR}$ & $\begin{array}{l}2.4042 \\
(0.996)\end{array}$ & -0.055 & $\begin{array}{l}-2.4210 \\
(0.0149)\end{array}$ & -0.051 \\
\hline \multirow{3}{*}{$\begin{array}{l}\text { With } \\
\text { Constant } \\
\text { and no } \\
\text { trend }\end{array}$} & $\operatorname{lnGDPR}$ & $\begin{array}{l}2.1969 \\
(1)\end{array}$ & -0.048 & $\begin{array}{l}-5.4371 \\
(0.000)\end{array}$ & 0.048 \\
\hline & $\operatorname{lnTAR}$ & $\begin{array}{l}-3.1509 \\
(0.023)\end{array}$ & 0.050 & $\begin{array}{l}-4.2369 \\
(0.000)\end{array}$ & 0.061 \\
\hline & InREXR & $\begin{array}{l}-0.6767 \\
(0.850)\end{array}$ & -0.058 & $\begin{array}{l}-3.3449 \\
(0.013)\end{array}$ & 0.020 \\
\hline \multirow{3}{*}{$\begin{array}{l}\text { With } \\
\text { Constant } \\
\text { and } \\
\text { Trend }\end{array}$} & $\operatorname{lnGDPR}$ & $\begin{array}{r}-1.7069 \\
(0.748)\end{array}$ & -0.082 & $\begin{array}{l}-6.8050 \\
(0.000)\end{array}$ & 0.058 \\
\hline & $\operatorname{lnTAR}$ & $\begin{array}{l}-2.7166 \\
(0.229)\end{array}$ & 0.041 & $\begin{array}{l}-4.9410 \\
(0.000)\end{array}$ & 0.062 \\
\hline & $\operatorname{lnREXR}$ & $\begin{array}{r}-1.2506 \\
(0.899)\end{array}$ & -0.066 & $\begin{array}{r}-3.3203 \\
(0.006)\end{array}$ & -0.024 \\
\hline
\end{tabular}

Critical Values

$\begin{array}{rr}1 \% & -2.613 \\ 5 \% & -1.948 \\ 10 \% & -1.613\end{array}$

Note: Probabilities are in parentheses. The optimal lags for the ADF tests are selected based on optimizing Schwarz Criterion using a range of lags. Tests for unit roots have been carried out on Gretl software. The level data were estimated better using the ADF that allows for both a constant term and a deterministic time trend which the plots of the data indicates.

Table II : Number of Optimal Lag Using SchwarzBayesian Criteria

\begin{tabular}{cc}
\hline Number of Lags & Schwarz-Bayesian Criteria \\
\hline 4 & -6.577873 \\
3 & -7.240160 \\
2 & -7.511907 \\
1 & $-7.917002^{*}$ \\
\hline
\end{tabular}

* indicates amount of optimal lag

According to the above table it can be claimed that optimal lag of the VAR model regarding the Schwarz Bayesian criteria is one. 
Table III : OLS Estimates, Using Observations

$$
\text { 1962-2011 ( } T=50)
$$

Dependent variable: 1_GDPR

Coefficient Std. Error t-ratio p-value

\begin{tabular}{ccccc}
\hline Const & 23.9190 & 0.1611 & 148.4 & $0.000^{* * *}$ \\
1_TAR & 0.0360 & 0.0170 & 2.114 & $0.039^{* *}$ \\
1_REXR & 0.5779 & 0.0370 & 15.61 & $0.000^{* * *}$
\end{tabular}

Note: ${ }^{* * *}$ and ${ }^{* *}$ denote significance of the variable at $1 \%$ and $5 \%$ respectively.

$\mathrm{R}^{2}: 0.9627 \quad$ Adjusted $\mathrm{R}^{2}: 0.9611$

$\mathrm{F}(2,47): 206.456 \quad$ P-value(F) : 0.000

Durbin-Watson: 0.178

Table III shows the significance of coefficients. The estimated elasicities have expected signs. The results indicate that a $1 \%$ increase in tourist arrivals to Nepal results to impact the increase of GDPR of Nepal about $3.6 \%$, which seems to be very low impact. Similarly, $1 \%$ increase in real effective exchange rate impacts about $57 \%$ growth of GDPR of Nepal, which is remarkable. Here, I have also saved the residual (uhat) for the purpose to use in error correction model.

Having estimated the model, we then proceed to test for cointegration using the residuals based method of Engle and Granger (1987). According to Engle and Granger, if the residuals obtained from the above static regression are stationary, it implies that the variables are cointegrated. Hence, there is a tendency for the variables to move together in the long-run even though the variable may wander or drift individually apart. Engle and Granger cointegration techniques test for the presence of a unit root in the residuals. This implies that the null of a unit root corresponds to cointegration at $10 \%$ level of significance. The results obtained using the Engle and Granger cointegration test is presented in Table V.
Table IV : Cointegrating Regression: OLS, Using

Observations 1962-2011 $(T=50)$

Dependent variable: 1_GDPR

\begin{tabular}{lcrrr}
\hline & \multicolumn{1}{c}{ Coefficient } & Std. Error & t-ratio & p-value \\
\hline Const & 26.0730 & 0.1052 & 247.6 & $0.000^{* * *}$ \\
1_TAR & -0.1044 & 0.0087 & -11.9 & $0.000^{* * *}$ \\
1_REXR & 0.1104 & 0.0217 & 5.080 & $0.000^{* * *}$ \\
time & 0.0397 & 0.0016 & 23.87 & $0.000^{* * *}$ \\
R $^{2}$ & 0.9972 & & & \\
Adj. R & 0.9970 & & & \\
Durbin- & 1.143 & & & \\
Watson & & & & \\
\hline
\end{tabular}

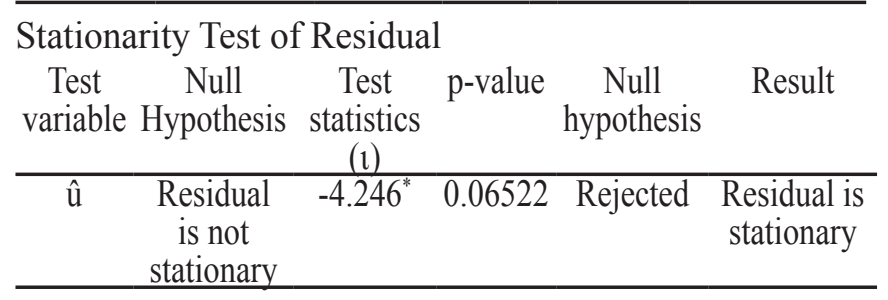

1st-order autocorrelation coeff. $\rho:-0.005$

Note: no autocorrelation on since rho $(\rho)$ value $=-0.005$ and upon calculation of

$d=2(1-\rho)$, it comes very near to 2 .

There is evidence for a cointegrating relationship because:

(a) The unit-root hypothesis is not rejected for the individual variables.

(b) The unit-root hypothesis is rejected for the residuals (uhat) from the cointegrating regression at $10 \%$ level of significance.

When applying the cointegration test, I choose the assumption where the level data has a linear trend. We notice that the null hypothesis of no cointegration relationships is rejected against the alternative of one cointegrating relationship at the $10 \%$ level. These results show that the single-equation estimation for an increase in tourism can capture the long-run relationship.

To circumvent the problem associated with the Engle and Grangers' methodology, we proceed to constructing an error-correction model for the variables. This is because the presence of a cointegrating relationship implies that there exists an error correction mechanism (ECM) that describes the short-run dynamics consistent with the long-run relationship. For the purpose I take the first 
difference of the variables and use OLS with the inclusion of $u$ hat and time trend, where $u$ hat has taken lag 1. The results of the ECM are presented in Table V.

Table V : Error Correction Model for Impact of Tourism on Economy

Dependent variable: $\Delta 1$ l_GDPR

\begin{tabular}{cccc}
\hline & Coefficient & t-ratio & p-value \\
\hline Const & 0.01229 & 1.833 & $0.0735^{*}$ \\
$\Delta$ l_TAR & 0.03721 & 1.643 & 0.1076 \\
$\Delta$ l_REXR & 0.04302 & 0.930 & 0.3573 \\
time & 0.00069 & 4.041 & $0.000^{* * *}$ \\
& -0.06330 & -2.660 & $0.0109^{* *}$ \\
\hline
\end{tabular}

$\mathrm{R}^{2}: 0.1472$ Adjusted $\mathrm{R}^{2}: 0.0696$

Durbin-Watson: 2.631

The error correction term _ 1 is significant and has the expected negative sign. The estimated coefficient of the error correction terms measure the speed of adjustment to restore equilibrium in the dynamic model. According to Table V, the pace of short-run error correction toward equilibrium and long-run state is about -0.063 . This clearly indicates that there is a very slow adjustment to the long-run equilibrium i.e. the speed of adjustment rate is about $6.3 \%$ for long-run equilibrium between tourism and GDPR.

\section{Conclusion}

This study investigated empirically the causal nexus between tourism and economic growth. This study also examined the short-run and long-run dynamics of the observed variables for the Nepalese context. Cointegration allows the estimation of long-run equilibrium relationship among economic variables, while ECM permits the modeling of the short-run and the long-run adjustments processes simultaneously. In this paper, I use the cointegration and error correction models to estimate econometric model for economic impact of tourism on Nepal's economy. This study investigates a series of unit root, cointegration and error correction tests to ascertain whether there is a long-run equilibrium between gross domestic product, tourist arrivals and real effective exchange rate in Nepal. Using annual data over the 1962-2011 period and since the variables in this paper are nonstationary and present a unit root, Engle and Granger's cointegration technique is applied. This methodology allowed us to obtain a cointegrating relationship among the three variables. The residual results of $\mathrm{ADF}$ test has rejected the null hypothesis of non- stationarity at $10 \%$ significance level and conformed that there is a long-run relationship between the tourism performance and economic growth. It can be claimed that there is a long-run relationship preventing them from diverging over time. In other words, the two variables follow each other over time.

Results of this study provide evidence in favor of 'demand following' hypothesis for the Nepalese context. Findings of the study suggest that the there is an important role of tourism performance on economic growth of the country. To the best of my knowledge, this is the first study to undertake both the variables (TAR and REXR) and growth variables (GDP) to study the economic impact of tourism on Nepal's economy using short-run and longrun dynamics by utilizing 50 years time series data. The main contribution of study is in identifying the role of tourism on economic growth.

Understanding of the relationship between tourism performance and economic growth may assist the researchers, practioners and planners in their estimates of the future planning of the tourism industry. This understanding is of significance for policy makers in developing policies to best suit economic objectives for the country.

A limitation of this study is the inability to account for structural change in the various models. The tourism industry is highly volatile and there is need to account for possibility of structural change in the model building in future study of economic impact of tourism on Nepal's economy. 


\section{References}

Balaguer, J. \& M. Cantavella-Jorda. (2002). Tourism as a long-run economic growth factor: the Spanish case. Applied Economics, 34, 877-884.

Dickey, D. \& W.A. Fuller. (1981). Likelihood ration statistics for autoregressive time series with a unit root. Econometrica, 49, 1057-1072.

Dritsakis, N. (2004). Tourism as a long-run economic growth factor: An empirical investigation for Greece using a causality analysis. Tourism Economics, 10, 305-316.

Durbarry, R. (2004). Tourism and economic growth: the case of Mauritius. Tourism Economics, 10, 389-401.

Enders, W. (2004). Applied Econometric Time Series, 2nd edn, John Wiley \& Sons, New Jersey.

Engle, RF \& Granger, CWJ. (1987). Cointegration and Error Correction: Representation, Estimation and Testing. Econometrica, 55, 251-276.

Eugenio-Martin, J.L. and N.M., Morales. (2004). Tourism and economic growth in Latin American countries: A panel data approach. Social Science Research Network Electronic Paper.

Granger, CWJ. (1983). Co-Integrated Variables and Error-Correcting Models, Discussion Paper 8313, University of California, San Diego, CA.

Gunduz, L.\& A., Hatemi-J. (2005). Is the tourism-led growth hypothesis valid for Turkey? Applied Economics Letters, 12(8), 499-504.
Johansen, S. (1988). Statistical analysis of cointegrating vectors. Journal of Economic Dynamics Control, $12,231-254$.

Lee, C.C., \& C.P., Chang. (2008). Tourism development and economic growth: A closer look at panels. Tourism Management, 29, 180-192.

Nelson, C.R. \& C.I., Plosser. (1982). Trends and Random Walks in Macroeconomic Time Series: Some evidence and implications. Journal of Monetary Economics, 10, 139-162.

Oh, C.O. (2005). The contribution of tourism development to economic growth in the Korean economy. Tourism Management, 26, 39-44.

Tang, C.F. (2011). Is the tourism-led growth hypothesis valid for Malaysia? A view from disaggregated tourism markets. International Journal of Tourism Research, 13(1), 97-101.

World Travel \& Tourism Council-WTTC. 2011. Nepal: Travel and Tourism Economic Impact, London: WTTC.

Zortuk, M. (2009). Economic Impact of Tourism on Turkey's economy: Evidence From Cointegration Tests. International Research Journal of Finance and Economics, 25, 231-239. 